\title{
Can serpentinisation processes provide brines for the ore-forming factory?
}

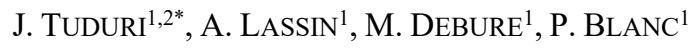 \\ ${ }^{1}$ BRGM, F-45060 Orléans, France \\ ${ }^{2}$ ISTO, UMR7327, Université d'Orléans, CNRS, BRGM, F- \\ 45071 Orléans, France
}

Serpentinisation processes occur in various settings where the mantle peridotites have been exhumed in hyperextendedrifted margins or along MOR. It may also continue during subduction, where fluids released from the slab may serpentinise the mantle wedge. Recent advances in marine geology about abyssal serpentinite systems reported an interesting discussion about the origin of sub-seafloor salt deposits in deep marine basins $[1,2]$.

Although there is considerable debate concerning the mechanisms and chemical reactions involved in the formation of serpentinites in submarine hydrothermal environments, the typical reaction that describes the conversion of olivine and Ca-poor pyroxene from mantle rocks into serpentine may be written as follows:

$\mathrm{Mg}_{2} \mathrm{SiO}_{4}+\mathrm{MgSiO}_{3}+2 \mathrm{H}_{2} \mathrm{O}+\mathrm{Na}^{+}+\mathrm{Cl}^{-} \Rightarrow \mathrm{Mg}_{3} \mathrm{Si}_{2} \mathrm{O}_{5}(\mathrm{OH})_{4}+\mathrm{NaCl}$.

In other words, serpentinisation reactions consume $\mathrm{OH}$ groups from seawater, which also contains about $3.5 \mathrm{wt} \%$ of dissolved salts and, in return, it increases the salinity of the remaining aqueous brines. Brines and possible precipitates obtained from super-saturation can be trapped in fractures and cavities in serpentinites. Serpentinisation is an ubiquitous, long-lasting process which can modify large volumes of oceanic lithosphere over geological times.

Moreover, this reaction exhibits a strong exothermal behavior $\left(\sim 35 \mathrm{~kJ} / \mathrm{mol} \mathrm{H}_{2} \mathrm{O}\right)$. It may represent the heat source responsible for non-volcanic, hydrothermal activity that may be at the origin of ore deposits.

We herein propose different thermodynamic models, using the geochemical code PhreeqC and the Pitzer database, in order to evaluate if brine formation by serpentinisation processes may directly or undirectly produce $\mathrm{Co}(-\mathrm{Ni}-\mathrm{As})$ deposits.

[1] Debure et al. (2019) Sci. Rep 9, 11720.

[2] Scribano et al. (2017) Int. J. Earth Sci 106, 2595-2608. 